\title{
Prevalence of Bovine Liver Abscess in Karbala Province in Iraq
}

\author{
Afaf A. R. Yousif, Mohammed A. Alkabi \\ Department of Veterinary Internal and Preventive Medicine, College of Veterinary Medicine, University of Karbala, Karbala, Iraq \\ Email address: \\ Afaf_a.rhman@yahoo.com (A. A. R. Yousif), Dr.mohammedassad_Alkabi@yahoo.com (Mohammed A. A.)

\section{To cite this article:} \\ Afaf A. R. Yousif, Mohammed A. Alkabi. Prevalence of Bovine Liver Abscess in Karbala Province in Iraq. American Journal of Applied \\ Scientific Research. Vol. 2, No. 4, 2016, pp. 17-21. doi: 10.11648/j.ajasr.20160204.11
}

Received: July 10, 2016; Accepted: July 14, 2016; Published: August 26, 2016

\begin{abstract}
Liver abscesses considered a major economic problem and there exists very less information in association with liver abscesses in bovine. Although studies in several countries have reported on the incidence of bovine liver abscesses at abattoirs, few surveys have identified the etiology and pathological characteristics of liver abscesses. The present study was conducted to evaluate the prevalence of liver abscesses in cattle in Karbala province in Iraq, during the interval which extended from July 2014 to April 2016, the livers of 125 animals in both sexes aged from $1^{\text {st }}$ to $8^{\text {th }}$ years were slaughtered in at the Karbala abattoir, the prevalence of liver abscess was high in cattle aged four years $(24 \%)$ while Sexes of animals were showed highly significant differences prevalence was high in female $(68 \%)$ than male $(32 \%)$. Also the gross evaluation of hepatic lesion according to liver abscess score showed high prevalence of score $(\mathrm{A}+)(\mathbf{7 0 \%})$ while the histopathological examinations of abscessed liver were observed abscess foci surrounding by the pyogenic membrane.
\end{abstract}

Keywords: Prevalence, Bovine Liver Abscess, Iraq

\section{Introduction}

The liver abscesses are one of the most challenging problems for the feedlot industry (Nagaraja and Lechtenberg, 2007). Liver abscesses are generally a direct result of feeding practices; diet is an important factor influencing the prevalence. (Smith, 1998)

The prevalence of liver abscess in cattle has been ranged $12-32 \%$ in slaughtered animals but can be at low percentage $1 \%$ to $2 \%$ to a high percentage $90 \%$ to $95 \%$, but averages $20 \%$ to $30 \%$ in most feedlots cattle in individual groups. (Brink et al., 1990)

The prevalence in the United States of America varies widely between feedlots cattle but ranges from $12-32 \%$ in most equivalent rates occur in 'barley beef' cattle, also the prevalence of liver abscesses was higher in feedlot steers than heifers. (Nagaraja et al., 1996,)

Liver abscess was formed $45 \%$ from causes of liver condemnations in slaughtered beef cattle in the United States. (Montgomery, 1992).

There are many factors which appear to be associated with the condition including the level of feeding, age of the animal and particularly the quality aspects of the feed which the cattle are offered (Nagaraja et al., 1996).

The high prevalence of liver abscess in cattle fed on a mixture of dry-rolled corn and dry-rolled wheat compared to dry-rolled corn alone (Stock et al., 1990).

Grain digestion, particularly gelatinization of the starch granules promoted the rate of ruminal fermentation of the starch so it increased the probability of acidosis and liver abscesses (Nagaraja et al., 2005,).

Liver abscess has been considered the major economic problem which responsible of contaminating livers which are associated with less feed intake, weight gain, and dressing percentage. Also, they increase trimming and as a consequence damage the profitability of feedlot producers and slaughter plant owners (Nagaraja and Lechtenberg, 2007)

Liver abscesses in cattle reduce feed intake, weight gain, feed efficiency, and dressing percentage so it was suggested that a relationship exists between the severity of liver abscesses and animal performance (Meyer et al., 2009)

Fusobacterium necrophorum is known to be the most common bacterial cause of liver abscesses. Fusobacterium necrophorum subspecies necrophorum, which are frequently isolated from abscessed livers along with other pathogenic 
bacteria (e.g., Arcanobacterium pyogenes). These bacteria attach to the ruminal wall and then penetrate from the area of lesion in the rumen epithelium and subsequently reach the portal blood and access the liver (Tadepalli et al., 2009)

Fusobacterium necrophorum have a role in ruminal fermentation mainly to utilize lactic acid and degrade protein, the organism is in higher concentration in grain-fed than forage-fed cattle, possibly because of the increased availability of lactic acid from starch fermentation (Smith, 2015)

The present study was performed to evaluate the prevalence of liver abscesses in cattle in Karbala province and to isolate the Fusobacterium necrophorum subspecies necrophorum, and pathological features associated with the occurrence of that case.

\section{Material and Methods}

\subsection{Studies Distract}

In the period between July 2014 to April 2016, the livers of 125 carcasses of cattle in both sex aged from ( $1^{\text {st }}$ to $8^{\text {th }}$ years $)$ slaughtered at the local industrial abattoir in (Karbala province in Iraq) were examined for abscesses. Assessment of the liver abscesses was scored to classify the severity of lesion according to (Brown et al., 1975). Liver was examined and sampling for bacterial culture and histopathology were collected.

Table 1. The liver abscess scoring system.

\begin{tabular}{ll}
\hline Score & Lesions \\
\hline A & one or two small, unorganized abscesses, or two to four \\
A + & well organized abscesses, or abscess scars \\
\hline
\end{tabular}

\subsection{Species Collection}

The specimens were collected from affected livers and transmitted to the laboratory under anaerobic conditions then it was added to the sterile tube containing BHI broth for bacterial culturing. Identification of anaerobic bacterial isolates was done using standard procedures (Carter et al., 1995; Tan et al., 1994)

\subsection{Histopathological Examination}

Samples from (liver) placed immediately in $10 \%$ formalin for histopathological examination. The histopathological section was processed according to (Luna, 1968).

The tissue samples were processed in an automated tissue processor for about 15 hours, the fixed specimens were processed and embedded in paraffin wax, section at 3-5 micron thickness prepared and stained with H\&E stain for histopathological examination (Sheehan et al., 1980).

\subsection{Statistical Analyses}

Statistical analyses for the results were done by Chi square test. $\mathrm{P}<(0.01)$ as a criterion for significant (Al- Mohammed et al., 1986)

\section{Results}

\subsection{Prevalence of Liver Abscess}

The gross examination of 125 were obtained from cows after slaughter have been showed multiple nodules varies in size which scattered on the hepatic surface (partial and visceral) as large nodules have sized about $0.5-1.5 \mathrm{~cm}$ which surrounded by thick membrane containing thick creamy or white-green pus or small abscess scattered in hepatic surface or within the parenchyma of liver, these nodules sized about $0.2 \mathrm{~cm}$ in diameter which filled with white yellow pus. According to liver scoring system the examination of infected livers revealed that the prevalence of score $(\mathrm{A}+)$ was higher than score $(\mathrm{A})$ with significant differences (Table 2).

Table 2. The severity of liver abscess in score.

\begin{tabular}{lll}
\hline Score & & \\
\hline & A & A+ \\
\hline & $\mathbf{4 0}(\mathbf{3 2} \%)$ & $\mathbf{8 5}(\mathbf{7 0} \%)$ \\
\hline Chi-square value & 16.20 & \\
$\mathrm{P}$ & $<0.0001$ & \\
\hline
\end{tabular}

\subsection{Prevalence of Liver Abscess According to Age of Animals}

The results revealed significant differences among the ages of animals the high prevalence of liver abscess showed in cattle aged three, four and five years old while low prevalence was occurred in cattle aged 1 year as table 3 .

Table 3. The prevalence of liver abscess according to age of animals.

\begin{tabular}{|c|c|c|c|c|c|c|c|}
\hline \multicolumn{8}{|l|}{ Age (year) } \\
\hline 1 & 2 & 3 & 4 & 5 & 6 & 7 & 8 \\
\hline $4(3)$ & $10(8 \%)$ & $20(16 \%)$ & $30(24 \%)$ & $25(20 \%)$ & $15(12 \%)$ & $15(12 \%)$ & $6(5 \%)$ \\
\hline Chi-square value & 36.72 & & & & & & \\
\hline $\mathrm{P}$ & $<0.0001$ & & & & & & \\
\hline
\end{tabular}

\subsection{Prevalence of Liver Abscess According to Sex of Animals}

Sex has been showed significant differences between the 
Table 4. The prevalence of liver abscess according to sex.

\begin{tabular}{ll}
\hline Sex & Female \\
\hline Male & $85(68 \%)$ \\
\hline $40(32 \%)$ & \\
Chi-Square value 16.20 & \\
$\mathrm{P}<0.0001$ & \\
\hline
\end{tabular}

\subsection{Results of Fusobacterium necrophorum Isolation from} Liver Abscess

After 48 hour incubation anaerobically at $37^{\circ} \mathrm{C}$ the colony of Fusobacterium necrophorum. sub necrophorum were appeared as round, grey, and shiny in appearance have diameter $1-5 \mu \mathrm{m}$. The staining of smears by gram stain have been showed the characteristic form of Fusobacterium necrophorum it was observed as gram-negative, long, nonbranching filamentous pleomorphic bacillus rang $100 \mu \mathrm{m}$ in diameter with parallel sides and blunt or tapering ends. The of biochemical test to isolates of Fusobacterium necrophorum was similar to stander procedure (Carter et al., 1995; Tan et al., 1994)

(Figure 1).

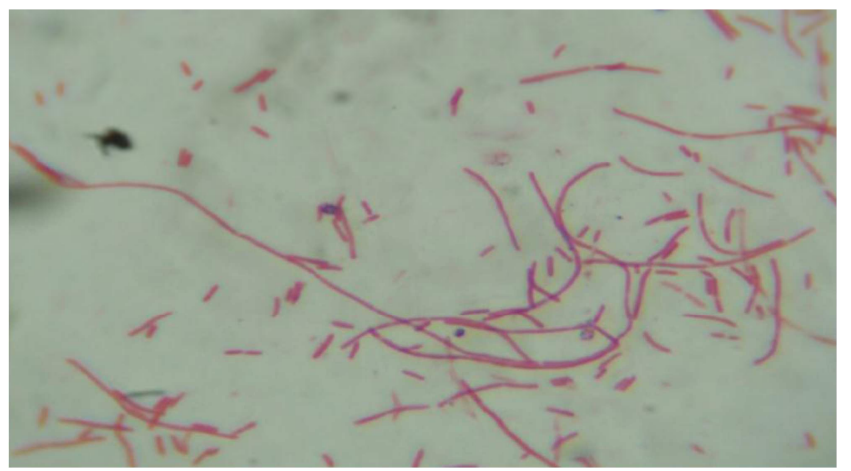

Figure 1. Fusobacterium necrophorum. Necrophorum gram-negative, long, non-branching filamentous bacillus.

\subsection{Results of Histopathological Examination}

The histopathological examination of abscessed livers have been revealed the lesion was characterized by abscess surrounded by the pyogenic membrane (Figure 2) as well as marked neutrophils infiltration and RBCs replacement sinusoids surrounded by the pyogenic membrane consisting from proliferation of fibrous connective tissue with neutrophils in the lumen of blood vessels (Figure 3) abscess with liquefactive necrosis showed in its center surrounded by marked thickness pyogenic membrane (Figure 4).

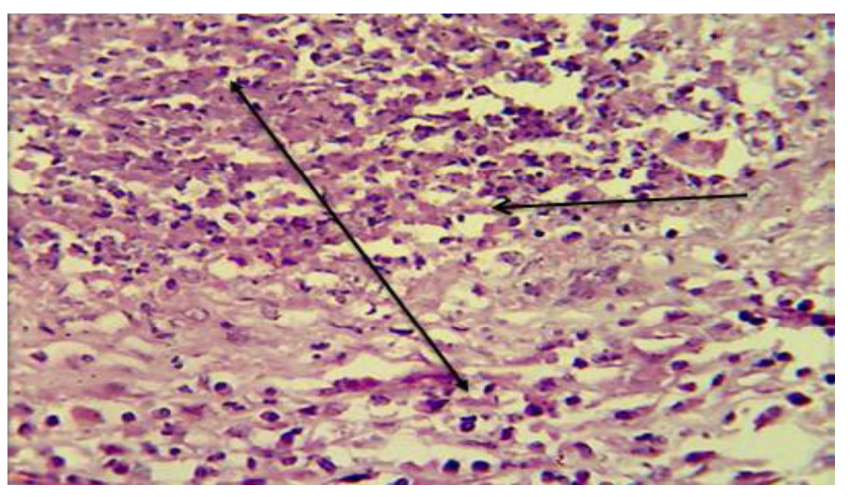

Figure 2. Histological section in liver shows abscess $\longrightarrow$ surrounded by pyogenic membrane $\longleftrightarrow$ (H\&E stain $4 O X)$.

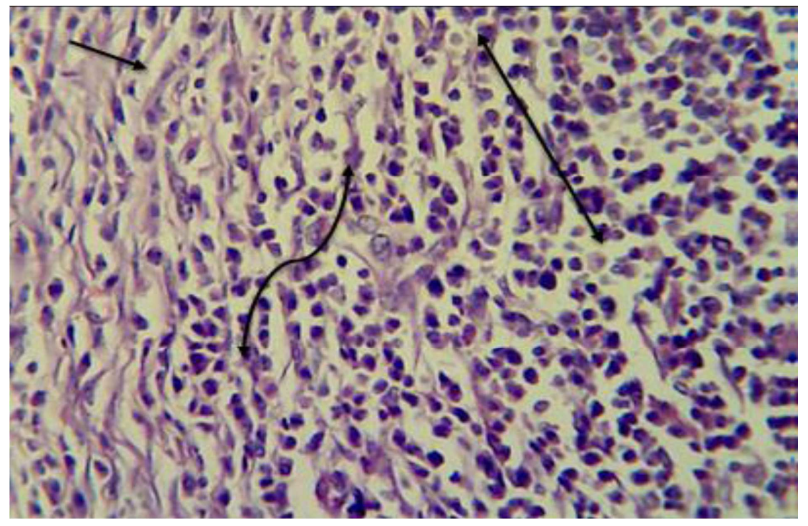

Figure 3. Histological section in liver shows marked neutrophils infiltration and $R B C s$ replacement sinusoids $\longleftrightarrow$ surrounded by pyogenic membrane consisting from proliferation of fibrous connective tissue $\longrightarrow$ with neutrophils in lumen of blood vessels

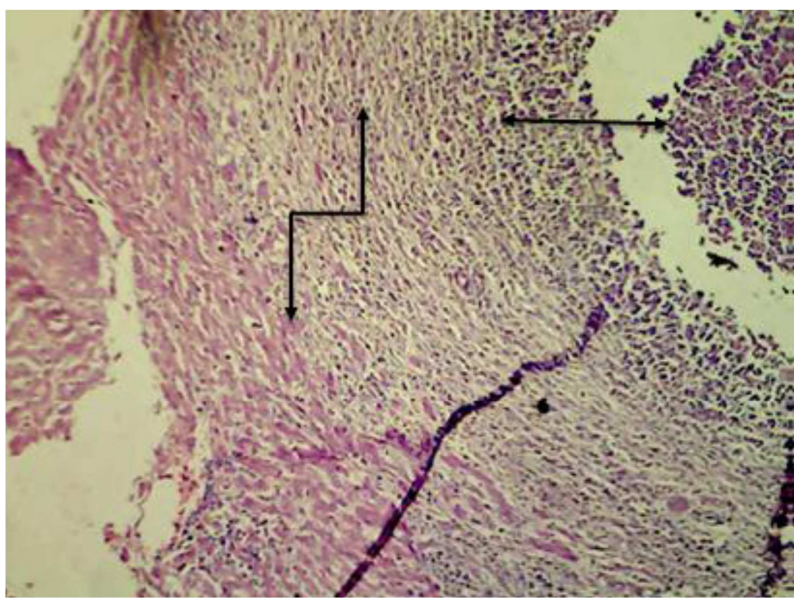

Figure 4. Histological section in liver shows abscess with liquifactive necrosis in its center surrounded $\longrightarrow$ by marked thickness pyogenic $\leftrightarrow \longrightarrow(H \& E$ stain 100X). 


\section{Discussion}

The results of gross examination of 125 liver from slaughter cattle have been showed multiple nodules varies in size which scattered on the hepatic surface (partial and visceral) as large nodules which surrounded by thick membrane containing thick creamy or white-green pus or small abscess scattered in hepatic surface or within the parenchyma of liver these results agreed with (Nagarajaand Chengappa, 1998; Aliasghar et al., 2012; Mohamed et al., 2013) mentioned abscesses in liver were filled with pus (contained a purulent yellowish-green or white, yellow and mucoid material) have capsules that vary in thickness, and size. The distribution of abscesses in the liver lobes shows no consistent pattern.

Evaluation of the liver lesion according to liver score system were reveled more significant of score $(\mathrm{A}+)$ then score (A) in most liver were examined, the reason of that the animal were infected with hepatic abscess not appeared any signs and the hepatic lesion were detected at the time of slaughter this agree with (Nagaraja et al.,1996; Smith,2015; Fox et al., 2009) who reported that the liver abscesses are detected only at the time of slaughter, because cattle, can that carried hundreds of small abscesses or several large abscesses, without showed any premonitory clinical signs.

The result revealed that the relation between prevalence of liver abscess and the age of animals, the abscess was occurred in all aged of animals but the animals aged 3, 4 and 5 years old showed high prevalence of hepatic abscess this could be attributed to the feeding management where the animals in this aged have high production so they fed on full grain ration to rise the productivity and this could led them to suffere from acidosis which led to rumenitis this result agreed with (Nagaraja and Lechtenberg, 2007 and Aliasghar et al., 2012) who reported the high prevalence of liver abscess occurred in sheep aged more than 5 months.

The results showed the prevalence of liver abscess in female was significantly higher than the males. This could be attributed to female is more susceptible to digestive disturbances specially pre and postpartum due to the feeding ratio which provided to animal at this period, which almost contain high fermentative food such as grains which causes acidosis. However, the results of the present study disagree with(Aliasghar et al., 2012) who reported there was no significant differences in incidence of liver abscess between male and female in sheep.

The severity of liver abscess in score $(\mathrm{A}+)$ attributed to the synergism of other bacteria with Fusobacterium necrophorum. This agreed with (Nagaraja et al., 1999; Nagaraja and Lechtenberg, 2007) who reported that the F. necrophorum and A. pyogenes, several other anaerobic and facultative bacteria have been isolated from bovine hepatic abscesses.

Fusobacterium necrophorum may isolate from hepatic abscess in cattle purely or mixed with other bacteria such as Staphylococcus aureus or Corynebacterium pyogenes from 25 cases of liver abscess (Fox et al., 2009)

The results of histopathological changes of liver abscess was revealed that the abscess surrounded by the pyogenic membrane, marked neutrophils infiltration and RBCs replacement sinusoids surrounded by pyogenic membrane consisting from proliferation of fibrous connective tissue these changes similar described by (Ahmed et al.,2013; ElDakhly et al., 2007 ). Also, agreed with (Raji et al.,who reported the histopathological examination for 268 abscessed livers showed well-circumscribed area of liquifactive necrosis surrounded by leucocyte infiltration and fibrosis.

The study was concluded that the liver abscess causes severe economic losses and Fusobacterium necrophorum subspecies necrophorum, causes liver abscess in cattle, cattle aged 4 and 3 years showed highly prevalence of liver abscess, liver abscess showed high prevalence in female than male.

\section{References}

[1] Nagaraja, T. G. and Lechtenberg, K. F. (2007). Liver Abscesses in Feedlot Cattle. Veterinary Clinics of North America: Food Animal Practice. 23: 351-369.

[2] Smith, R. A. (1998). Impact of disease on feedlot performance: A review. American Society of Animal Science. 76: 272-274.

[3] Brink, D. R., Lowry, S. R., Stock, R. A. and Parrott, J. C. (1990). Severity of liver abscesses and efficiency of feed utilization of feedlot cattle. J. Anim. Sci. 68: 1201-1207.

[4] Nagaraja, T. G., Laudert, S. B. and Parrott, J. C. (1996). Liver abscesses in feedlot cattle. Part I. Causes, pathogenesis, pathology, and diagnosis. Compendium on continuing education for the practising veterinarian. 18: S230-S256.

[5] Nagaraja, T. G., Laudert, S. B. and Parrott, J. C. (1996). Liver abscesses in feedlot cattle. Part II. Incidence, economic importance, and prevention. Compendium on continuing education for the practising veterinarian. 18: S264-S273.

[6] Nagaraja, T. G. and Chengappa, M. M. 1998. Liver abscesses in feedlot cattle: A review. American Society of Animal Science. 76: 287-298.

[7] Nagaraja, T. G., Beharka, A. B., Chengappa, M. M., Carroll, L. H., Raun, A. P., Laudert, S. B. and Parrott, J. C. (1999). Bacterial flora of liver abscesses in feedlot cattle fed tylosin or no tylosin. American Society of Animal Science. 77: 973-978.

[8] Nagaraja, T. G., Narayanan, S. K., Stewart, G. C. and Chengappa, M. M. (2005). Fusobacterium necrophorum infections in animals: Pathogenesis and pathogenic mechanisms. Anaerobe. 11: 239-246.

[9] Nagaraja, T. G. and Lechtenberg, K. F. (2007). Liver Abscesses in Feedlot Cattle. Veterinary Clinics of North America: Food Animal Practice. 23: 351-369.

[10] Montgomery, T. H. (1992). Improving the consistency and competitiveness of beef. National Beef Quality Audit-1991. Pp 144-147. National Cattlemen's Association, Denver, CO.

[11] Tadepalli, S., Narayanan, S. K., Stewart, G. C., Chengappa, M. M. and Nagaraja, T. G. (2009). Fusobacterium necrophorum: A ruminal bacterium that invades liver to cause abscesses in cattle. Anaerobe. 15: 36-43. 
[12] Stock, R. A., M. H. Sindt, J. C. Parrott, and F. K. Goedeken. (1990). Effects of grain type, roughage level and monensin level on finishing cattle performance. J. Anim. Sci. 68: 3441-3455.

[13] Meyer, N. F., Erickson, G. E., Klopfenstein, T. J., Greenquist, M. A., Luebbe, M. K., Williams, P. and Engstrom, M. A. (2009). Effect of essential oils, tylosin, and monensin on finishing steer performance, carcass characteristics, liver abscesses, ruminal fermentation, and digestibility. J. Anim. Sci. 87: 2346-2354.

[14] Smith, B. P (2015). Large Animal Internal Medicine, 4th Ed. Mosby-Elsevier Publishing. St. Louis, MO.

[15] Brown, H., R. F. Bing, H. P. Grueter, J. W. McAskill, C. O. Cooley, and R. P. Rathmacher. (1975). Tylosin and chlortetracycline for the prevention of liver abscesses, improved weight gains and feed efficiency in feedlot cattle. J. Anim. Sci. 40: 207-213.

[16] Carter, G. R., M. M. Chengappa, and A. W. Roberts. (1995). Essentials of Veterinary Microbiology $\left(5^{\text {th }}\right.$ Ed.). Williams and Wilkins, Philadelphia, PA.

[17] Tan, Z. L., Nagaraja T. G., and Chengappa M. M. (1994). Biochemical and biological characterization of ruminal Fusobacterium necrophorum. FEMS Microbiol. Lett. 120: 81-86.

[18] Luna LG (1968). In Manual of Histological Staining Methods of the Armed Forces Institute of Pathology. ( $3^{\text {rd }}$ edition), New York: McGraw Hill.

[19] Sheehan, D. C. and Hrapchak, B. B. (1980) Theory and Practice of Histotechnology. $2^{\text {nd }}$ edition, The CV Mosby Company, St Louis.
[20] Al-Mohammed, N. T.; Al-Rawi, Kh. M.; Khames, M. A. and Al-Marani, W. Kh. (1986). Principles of Statistics. Ministry of Higher Education and Scientific Research. Baghdad University.

[21] Aliasghar, T., Javanbakht, J., Hassan, MAM., Zamani, M., Rajabian, M. (2012) Histopathological and Bacteriological Study on Hepatic Abscesses of Herrik Sheep. Med Microb Diagn 1: 115 .

[22] Mohamed G. E. Borai, Abdel-Rehiem A. Nagi, Mahmoud S. Gab-Allah, Abdel-Baset I. El- Mashad and Shawky A. Mustafa. (2013). Comparative pathological study on bacterial effect of liver in farm animals. BVMJ - 25 (2): 296-305.

[23] Fox, J. T., Thomson, D. U., Lindberg, N. N. and Barling, K. (2009). A comparison of two vaccines to reduce liver abscesses in natural-fed beef cattle. Bovine Practitioner. 43: 168-174.

[24] Ahmed A. M., Ismail S. A. S. and Dessouki A. A. Pathological lesions survey and economic loss for male cattle slaughtered at Ismailia abattoir. Int. Food Res. J. 20 (2): 857-863.

[25] El-Dakhly, K. M., Hassan, W. H. and Lotfy, H. S. (2007). Some parasitic and bacterial causes of liver affections in ruminants. $5^{\text {th }}$ Scientific Conference, BS. Vet. Med. J. 2: 6268 .

[26] Raji, M. A., Salami, S. O. and Ameh, J. A. (2010). Pathological conditions and lesions observed in slaughtered cattle in Zaria abattoir. Journal of Clinical Pathology and Forensic Medicine. 1 (2): 9-12. 